\title{
PEMANFAATAN LIMBAH TERNAK SAPI DI KELOMPOK TANI TERNAK SUKATINGGI-1 KAMPUNG CISARONI- LEMBANG
}

\author{
Purwinda Iriani, Yanti Suprianti, Apip Pudin \\ Jurusan Teknik Konversi Energi, Politeknik Negeri Bandung \\ Jl. Gegerkalong Hilir, Desa Ciwaruga, Ciwaruga, Parongpong, Kabupaten Bandung Barat, Jawa Barat \\ 40012, Indonesia \\ Email: purwinda.iriani@polban.ac.id, yantisuprianti.ys@gmail.com, apip055@yahoo.com
}

\begin{abstract}
ABSTRAK
Berdasarkan data Dinas Peternakan tahun 2014, kegiatan ternak sapi perah di Jawa Barat mampu menghasilkan 254.361.179 L susu sapi dengan 31,02\% dipasok dari Kabupaten Bandung Barat (Disnakjabar, 2015). Aktivitas ternak sapi perah tersebut, tentunya turut menghasilkan limbah berupa kotoran sapi. Potensi limbah kotoran sapi yang dihasilkan mampu mencapai 185 ton/hari di wilayah Bandung Barat. Limbahlimbah tersebut ada yang telah dimanfaatkan sebagai pupuk alami dan untuk pembuatan biogas. Namun, sebagian limbah yang belum termanfaatkan hanya dibuang/disalurkan menuju aliran pembuangan air yang bermuara ke Daerah Aliran Sungai (DAS) Citarum. Salah satu dampak nyata dari belum optimalnya pemanfaatan dan pembuangan langsung limbah tersebut adalah menurunnya kualitas air. Selain itu, pemanfaataan kotoran sapi untuk menjadi bahan baku pembuatan biogas masih belum diketahui dengan baik oleh para peternak sapi. Kondisi tersebut dijumpai di salah satu kelompok usaha tani ternak sapi daerah Lembang-Bandung. Berdasarkan hal tersebut, telah dilakukan upaya pemanfaatan limbah kotoran ternak sapi melalui program Pengabdian kepada Masyarakat yang diselenggarakan UPPM Polban, tim P2M dari Jurusan Teknik Konversi Energi, yakni melalui kegiatan pemanfaatan limbah ternak sapi perah untuk produksi biogas. Unit masyarakat yang dijadikan mitra dalam hal ini adalah kelompok usaha Tani Ternak Sapi Sukatinggi 1, Kampung Cisaroni, Desa Cikahuripan, Lembang-Bandung. Dari kegiatan Pengabdian kepada Masyarakat ini, telah menghasilkan luaran yakni instalasi biodigester kapasitas $5 \mathrm{~m}^{3}$ beserta perangkat pendukungnya, modul pelatihan, dan SOP pengoperasian.
\end{abstract}

Kata kunci : pemanfaatan limbah, biogas, kelompok tani ternak sapi, pengabdian kepada masyarakat

\section{PENDAHULUAN}

Berdasarkan data Jawa Barat Dalam Angka 2015, populasi sapi perah Jawa Barat hingga tahun 2014 mencapai 123.140 ekor, yang mayoritas berada di Kabupaten Bandung Barat (30,28\%) dan Kabupaten Bandung (27,32\%). Dari industri sapi perah tersebut dihasilkan 254.361.179 liter susu sapi selama tahun
2014, dengan 31,02\% produksi susu sapi dihasilkan di Kabupaten Bandung Barat, yang terkonsentrasi di wilayah Lembang. Kegiatan peternakan selain menghasilkan susu sapi, juga menghasilkan kotoran ternak yang sebenarnya cukup potensial bila dimanfaatkan secara optimal. Menurut Ketua Pusat Kegiatan Belajar 
DIFUSI

Volume 1, No.1, Januari 2018

Masyarakat (PKBM) Desa Wangunsari, Bapak Agus R. Subandi, S.Pd., selama ini kotoran sapi sebagian (50\%) sudah dimanfaatkan, tetapi sisanya dibuang sehingga menimbulkan bau, mencemari saluran air dan sungai (Renosori, 2012). Kelompok Tani Ternak Sukatinggi 1 merupakan kelompok dari para peternak sapi yang berada di Kampung Cisaroni, Desa Cikahuripan, Lembang - Bandung Barat yang telah beranggotakan 31 anggota yang masing-masing memiliki rata-rata 2 ekor sapi. Kandang peternakan yang dimiliki anggota ada yang ditempatkan di samping tempat tinggal, namun juga ada yang dikelola bersamasama pada satu tempat. Beberapa kendala dan potensi pengembangan dari kegiatan kelompok tani ini adalah adanya penumpukan limbah kotoran sapi (timbulan kotoran dikumpulkan dan dibiarkan di tempat terbuka) dan tempat aktivitas manusia sehari-hari (memasak, mandi, MCK) berada tepat di samping timbunan kotoran sapi, yang kemudian

limbah tersebut dibuang ke aliran yang mengarah ke area terbuka. Permasalahan lainnya adalah kompor yang digunakan untuk kebutuhan memasak salah satu anggota kelompok ternak masih menggunakan kayu bakar dan beberapa kandang sapi belum dilengkapi fasilitas instalasi biogas (Gambar 1). Berdasarkan permasalahan tersebut, terdapat peluang dalam pemanfaatan limbah kotoran sapi melalui kegiatan sosialisasi / penyuluhan tentang pemanfaatan kotoran sapi untuk dijadikan biogas dan tentang penanganan limbah agar tidak mencemari lingkungan serta instalasi perangkat digester biogas.

\section{METODE}

Metode pelaksanaan yang dilakukan pada pengabdian kepada masyarakat di lingkungan Kelompok Tani Ternak Sukatinggi 1 berangkat dari pendekatan hasil analisis situasi yang dijumpai dan disepakati oleh Mitra sebagai bentuk solusi yang ditawarkan (Gambar 2).

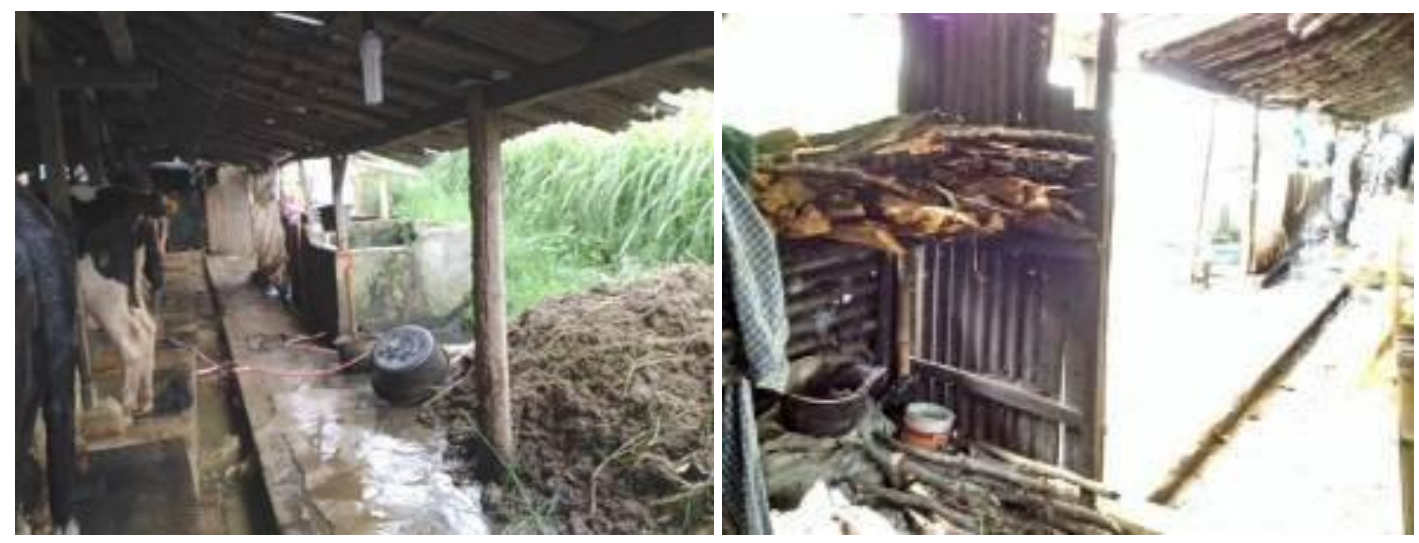

Gambar 1. Timbulan kotoran sapi (kiri) dan kompor kayu bakar yang berada di tempat tinggal anggota kelompok tani ternak sapi (kanan) 


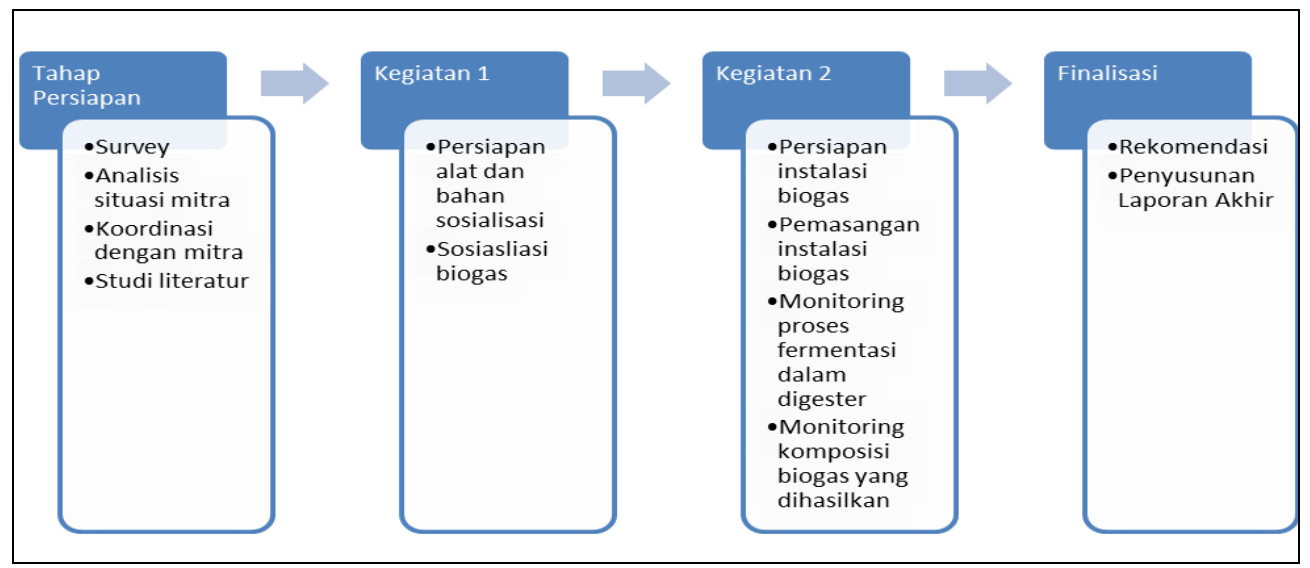

\section{Gambar 2. Diagram Tahap Pelaksanaan Kegiatan PKM}

$\underline{\text { Tahap Persiapan }}$

- Survey. Pada tahap ini tim pengabdian masyarakat melakukan visitasi lapangan ke tempat mitra, yakni ke Kampung Cisaroni, Desa Cikahuripan, tempat Kelompok Tani Ternak Sapi Sukatinggi 1 berlokasi. Metode yang digunakan dalam tahap ini adalah wawancara dan pengambilan dokumentasi di lokasi. Wawancara dilakukan langsung dengan ketua kompok Tani Ternak Sukatinggi 1. Dari hasil analisis yang diperoleh, maka dirumuskan dan dipilih masalah yang telah dijustifikasi oleh mitra.

- Koordinasi dengan mitra. Pada tahap ini hasil justifikasi permasalahan telah disepakati oleh mitra dan perumusan serta penentuan tujuan kegiatan pengabdian dapat dibuat. Dari hal tersebut muncul bentuk-bentuk solusi yang ditawarkan oleh tim P2M Jurusan Teknik Konversi Energi (JTKE) yaitu workshop / sosialisasi, penerapan teknologi pemanfaatan limbah, monitoring, dan lain-lain. Bentukbentuk solusi yang ditawarkan tersebut, tentunya memerlukan koordinasi dengan mitra agar tujuan kegiatan P2M tercapai.

- Studi Literatur. Tim P2M JTKE melakukan penelusuran referensi yang berkaitan dengan upaya-upaya pemanfaatan limbah dari peternakan sapi yang dapat menjadikan nilai tambah bagi suatu sistem dan atau taraf hidup peternaknya.
Kegiatan I (Pertama)

- Persiapan alat dan bahan. Dalam hal ini tim P2M JTKE dan mitra saling berkoordinasi mengenai persiapan pelaksanaan kegiatan pengabdian yang berkaitan dengan sarana prasarana yang dibutuhkan dan supporting tools yang dibutuhkan selama kegiatan P2M berlangsung.

- Workshop. Pada tahap ini tim P2M JTKE akan memberikan sosialisasi mengenai pengenalan terhadap jenis-jenis limbah yang dihasilkan dari suatu peternakan sapi, dampak yang ditimbulkan bagi kesehatan manusia dan lingkungan sekitar, serta hal utama, yaitu pemanfaatan limbah kotoran sapi untuk menaikkan nilai tambah bagi peternak sapi itu sendiri. Hal ini terkait perilaku penghematan penggunaan energi. Luaran dari kegiatan ini adalah modul workshop mengenai dampak cemaran limbah kotoran sapi, pemanfaatan, serta proses instalasi dan operasi biodigester.

\section{Kegiatan II (Kedua)}

- Persiapan Instalasi Biogas. Pada tahap ini dilakukan survey tempat produksi biodigester dengan kapasitas yang disesuaikan dengan kebutuhan mitra dan dana kegiatan, serta pengadaan alatalat pendukungnya, seperti gas holder, kompor biogas, dan lain-lain. Dari pihak mitra, dilakukan penyiapan lahan/ruang untuk tempat instalasi biodigester. Hal lain yang perlu diperhatikan dan dikoordinasikan bersama dengan mitra adalah instalasi 
sistem pembuangan kotoran sapi yang alirannya dapat menyesuaikan dengan proses instalasi biogas nantinya.

- Pemasangan Instalasi Biogas. Pada kegiatan ini dilakukan instalasi peralatan utama dan pendukung biodigester, bersama-sama oleh tim P2M dan mitra. Rencana biodigester yang akan dipasang adalah berkapasitas $5 \mathrm{~m}^{3}$. Selanjutnya dilakukan tahap demonstrasi pengolahan kotoran sapi sebelum masuk ke dalam biodigester, serta hal-hal yang perlu diperhatikan selama pengoperasian dan penggunaan biogas yang berhasil diproduksi.

- Monitoring proses fermentasi. Hal ini dilakukan selama proses fermentasi kotoran sapi berlangsung dan tahap selama kapasitas biodigester terus diisi hingga kapasitas maksimal. Pada proses pembentukan biogas, diperlukan waktu hingga 3-4 minggu. Hal tersebut membutuhkan pengawasan selama proses fermentasi berlangsung, yakni memastikan tidak terdapatnya

\section{HASIL DAN PEMBAHASAN}

Pada kegiatan tahap pertama, kegiatan pembuka dari program PkM adalah acara sosialisasi / workshop. Proses ini dapt berlangsung dengan lancar, melalui proses persiapan alat dan bahan oleh tim P2M JTKE dan koordinasi efektif bersama mitra. Workshop dilaksanakan di kediaman Ketua Kelompok Ternak Sapi Sukatinggi 1 kebocoran pada peralatan utama dan pendukung, pemeriksaan ada tidaknya produksi gas, dan lain-lain.

\section{Tahap Finalisasi}

- Rekomendasi. Pada tahap ini tim P2M JTKE akan memberikan rekomendasi kepada mitra terkait upaya-upaya pengelolaan lain dari kotoran sapi yang dapat menghasilkan nilai tambah. Selain itu, hasil analisis atau temuan yang diperoleh selama proses monitoring dan proses produksi biogas, akan disampaikan. Rekomendasi dapat berupa SOP, rambu-rambu, atau bentuk lainnya.

- Penyusunan laporan akhir. Tim P2M JTKE akan menyusun dan melaporkan hasil kegiatan pengabdian masyarakat bersama Kelompok Tani Ternak Sapi Sukatinggi 1, kepada UPPM Polban. Laporan kegiatan P2M tersebut juga akan diserahkan kepada mitra.

(Gambar 3). Tema dari kegiatan workshop adalah "Pemanfaatan Limbah Ternak Sapi untuk Produksi Biogas Kelompok Tani Ternak Sapi Sukatinggi - Desa Cisaroni - Lembang“'. Kegiatan ini diikuti oleh anggota kelompok Tani, dosen, dan mahasiswa Jurusan Teknik Konversi Energi Polban.
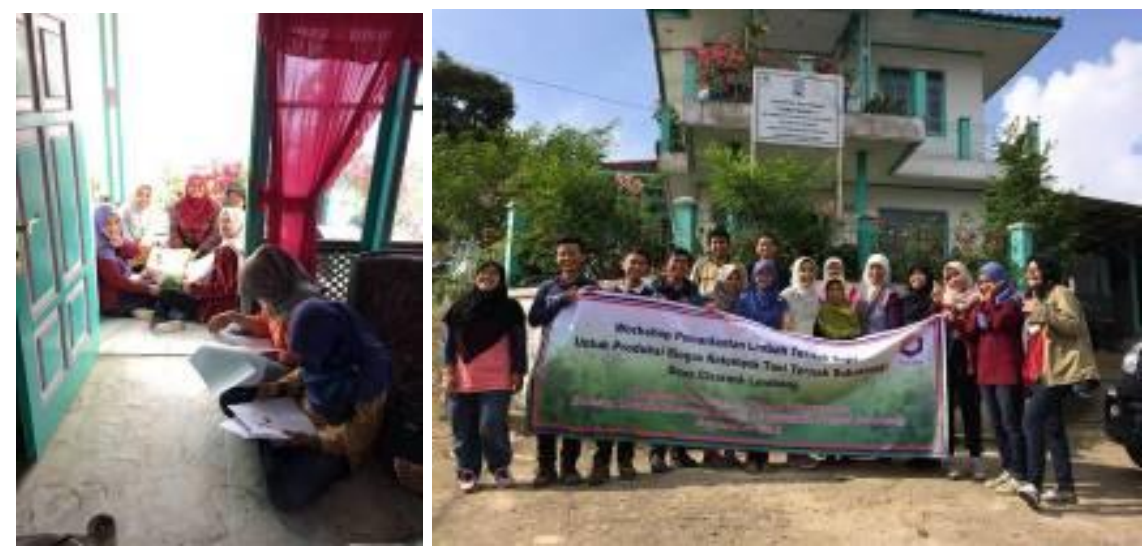

Gambar 3. Kegiatan Sosialisasi dan Proses Instalasi Biogas 
Pada kegiatan workshop, materi mengenai biogas, proses produksi biogas dari kotoran sapi, prosedur penggunaan biogas pada kompor gas dan manfaat yang diperoleh dari pemanfaatan kotoran sapi sebagai bahan baku biogas, diberikan oleh pemateri kepada mitra. Setelah sosialisasi/workshop dilakukan, maka tahap selanjutnya adalah instalasi digester biogas. Pada tahap instalasi ini, tim P2M dibantu oleh pihak penyedia Biodigester (Prima Energi Indonesia) dalam proses perakitan dan pemasangan biogas, serta dibantu oleh mitra yang telah menyediakan dan menggali tanah untuk implan biodigester. Selain itu, terlibat juga mahasiswa Jurusan Teknik Konversi Energi Polban yang membantu persiapan instalasi biodigester. Tempat biodigester akan ditanam sekitar $200 \mathrm{~m}$ dari tempat workshop, dan karena area yang susah dijangkau oleh kendaraan roda 4 (harus melalui lembah dan jalan setapak), maka biodigester dan peralatan penunjang lainnya dibawa dalam bentuk partisi. Tahap persiapan, perakitan, dan instalasi perlengkapan biodigester dapat dilihat pada Gambar 4.

Tahap selanjutnya setelah instalasi biodigester adalah tahap monitoring produksi biogas. Mitra melakukan pengisian kotoran sapi sebanyak $30 \mathrm{~L}$ hingga $50 \mathrm{~L}$ per hari. Selama pengisian bahan, turut pula dilakukan pemantauan terhadap produksi gas yang dihasilkan. Pada minggu pertama pengisian, biodigester telah terisi $30 \%$ dan instalasi dalam keadaan operasi normal, tidak terdapat kebocoran pipa, clogging, maupun kebocoran gas. Proses pemantauan dilakukan bersama-sama oleh tim P2M Jurusan Teknik Konversi Energi dan pihak Prima Energi Indonesia (penyedia instalasi biodigester). Gambaran instalasi biodigester pasca instalasi dapat dilihat pada Gambar 5.
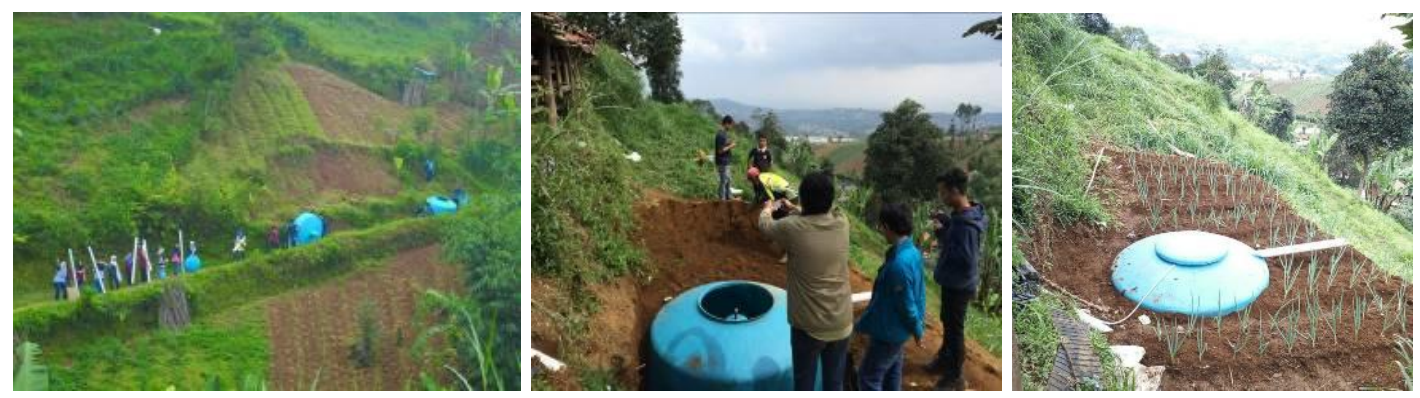

Gambar 4. Proses instalasi digester biogas dan penanaman digester

Setelah 10 hari pengisian biodigester hingga penuh, monitoring kembali dilakukan. Hari ke-4 setelah biodigester terisi penuh, produksi gas telah ada dengan ditunjukkan manometer di level 40. Namun pada pengujian nyala gas pada kompor, belum terdapat nyala api. Hal tersebut menandakan pembentukan gas Karbon dioksida masih mendominasi komposisi biogas yang terbentuk. Pada monitoring minggu ke-3, dilakukan monitoring kembali dan pihak Prima Energi Indonesia melaporkan bahwa gas Metana belum terbentuk. Tindak lanjut yang dilakukan adalah pemeriksaan kekentalan bahan baku campuran kotoran sapi dan air, dan disimpulkan bahwa bahan masukan terlalu cair. Hal tersebut mempengaruhi produksi gas Metana pada biogas belum optimal. Namun, konsentrasi masukan campuran kotoran sapi yang terlalu cair ini, ternyata dibuat 
untuk menyesuaikan kelancaran pengisian, karena dengan konsentrasi yang sesuai dengan ketentuan (kotoran sapi : air = 1 : 1) agak sulit untuk mengalirkan melalui pipa yang telah terpasang. Untuk dapat mengalirkan dengan lancar input campuran kotoran sapi dan menjaga kesesuaian konsentrasinya agar sesuai dengan ketentuan, maka pihak mitra dan Prima Energi Indonesia melakukan penyesuaian konstruksi pemasangan pipa. Penyesuaian

pipa masukan dilakukan dengan memperdalam saluran pipa dan menyesuaikan kemiringannya. Pasca penyesuaian instalasi saluran bahan masukan biodigester dan penyesuaian kembali kekentalan bahan baku, maka produksi gas Metana akhirnya terlihat tepat satu (1) bulan setelah instalasi. Kompor biogas dapat dinyalakan dan digunakan dari hasil gas Metana yang diproduksi biodigester (Gambar 5).
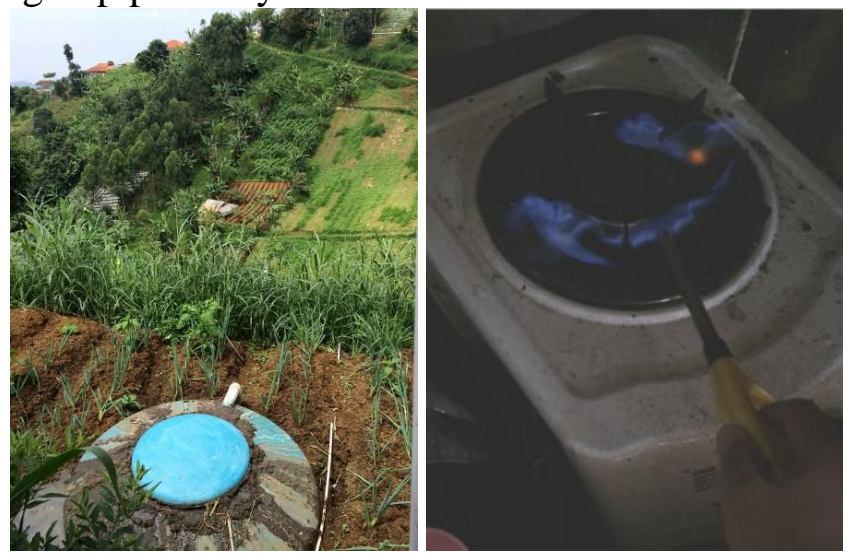

Gambar 5. Pasca Instalasi Digester (kiri) dan Nyala Api Biogas yang Dihasilkan (kanan)

Dengan diproduksinya biogas yang mengandung Metana yang mencukupi, maka secara berangsur konsumsi energi mitra yang tadinya menggunakan bahan bakar lain beralih ke biogas. Selain manfaat yang dirasakan oleh mitra, anggota kelompok tani yang lain pun menunjukkan minat untuk pemasangan biodigester untuk produksi biogas ini. Hal ini menunjukkan bahwa kegiatan pengabdian kepada masyarakat ini memberikan kepuasan bagi mitra.

Tahap akhir dari kegiatan pengabdian masyarakat ini adalah pemberian rekomendasi pada mitra terkait upaya pemanfaatan hasil akhir pembuatan biogas. Kegiatan usaha mitra dan anggotanya tidak hanya menjadi peternak sapi perah, namun beberapa juga menjadi petani yang mengelola perkebunan tomat, brokoli, kubis, dan sayuran lainnya.
Kepada mitra, tim P2M memberikan rekomendasi dalam pemanfaatan output slurry kotoran sapi yang keluar dari biodigester, untuk dijadikan pupuk alami dan pendamping pupuk yang mereka harus beli. Selain itu, direkomendasikan potensi usaha penjualan pupuk cair dari hasil fermentasi kotoran sapi yang dijadikan bahan baku pembuatan biogas.

Tahap finalisasi lainnya adalah pembuatan laporan kegiatan pengabdian masyarakat kepada Unit Penelitian dan Pengabdian Masyarakat (UPPM) Polban. Pada tahap ini dilakukan penyusunan laporan akhir dan dokumen administratif yang mendukung program ini terlaksana dengan baik.

\section{KESIMPULAN}

Kegiatan pengabdian kepada masyarakat yang dilakukan antara Jurusan Teknik 
Konversi Energi dan mitra Kelompok Tani Ternak Sapi Sukatinggi 1 Desa Cisaroni - Lembang, menghasilkan beberapa output dan luaran, yakni :

1. Telah dilakukan sosialisasi dalam rangka peningkatkan pemahaman peternak sapi dalam pengolahan kotoran sapi serta pemanfaatannya sebagai bahan baku pembuatan biogas.

2. Instalasi biodigester berkapasitas $5 \mathrm{~m}^{3}$ dan instalasi pendukungnya (seperti selang biogas, alat pemurnian gas, dan kompor gas) telah terpasang dan berhasil dioperasikan dalam memproduksi biogas.

3. Melalui pengenalan dan pelaksanaan sesuai modul Standard Operating Procedur (SOP), pengoperasian digester biogas hingga penggunaannya pada kompor, mitra sudah mampu memanfaatkan biogas yang diproduksi untuk kebutuhan sehari-hari.

\section{REFERENSI}

- BPS Provinsi Jawa Barat. 2015. "Jabar Dalam Angka 2015". (http://jabar.bps.go.id/new/website/pd f_publikasi/Jawa-Barat-DalamAngka-2015.pdf)

- nationalgeographic.co.id (diakses 17 Maret 2016)

- pikiranrakyat.co.id (terbit 2 September 2015)

- Statistik Pertanian, 2014, source : http://www.pertanian.go.id

- Puspitasari R., Muladno.,Atabany A.,dan Salundik. Produksi Gas Metana (CH4) dari Feses Sapi FH Laktasi dengan Pakan Rumput Gajah dan Jerami Padi, 2015

- Renosari P., Kajian Peningkatan Pemanfaatan Kotoran Sapi menjadi Biogas dengan Metode SWOT dan AHP di Desa Wangunsari Kecamatan Lembang, Buana Science, Vol. 12 No.1: 109-116, 2012 